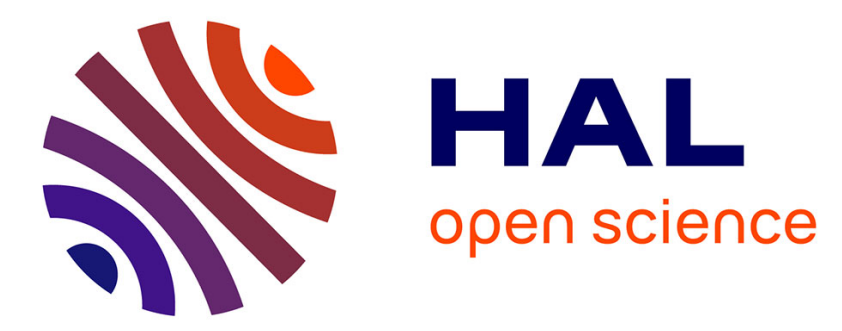

\title{
Tertiary Enamide-Promoted Diastereoselective Domino: N-Acyliminium Ion Trapping and Nazarov Cyclization
}

\author{
Yongxiang Zheng, Lucile Andna, Olivia Bistri, Laurence Miesch
}

\section{To cite this version:}

Yongxiang Zheng, Lucile Andna, Olivia Bistri, Laurence Miesch. Tertiary Enamide-Promoted Diastereoselective Domino: N-Acyliminium Ion Trapping and Nazarov Cyclization. Organic Letters, 2020, 10.1021/acs.orglett.0c02251 . hal-02929891

\section{HAL Id: hal-02929891 \\ https://hal.science/hal-02929891}

Submitted on 4 Sep 2020

HAL is a multi-disciplinary open access archive for the deposit and dissemination of scientific research documents, whether they are published or not. The documents may come from teaching and research institutions in France or abroad, or from public or private research centers.
L'archive ouverte pluridisciplinaire HAL, est destinée au dépôt et à la diffusion de documents scientifiques de niveau recherche, publiés ou non, émanant des établissements d'enseignement et de recherche français ou étrangers, des laboratoires publics ou privés.

\section{(c) (1) $\$$}

Distributed under a Creative Commons Attribution - NonCommerciall 4.0 International 


\title{
Tertiary Enamide-Promoted Diastereoselective Domino : $\mathbf{N}$-Acylimin- ium Ion Trapping and Nazarov Cyclization
}

\author{
Yongxiang Zheng, ${ }^{[\mathrm{a}]}$ Lucile Andna, ${ }^{[\mathrm{a}]}{ }^{\dagger}$ Olivia Bistri, ${ }^{[\mathrm{b}]}$ and Laurence Miesch $^{[\mathrm{a}]^{*}}$
}

[a] Laboratoire de Chimie Organique Synthétique, Institut de Chimie, CNRS-UdS, UMR 7177,4 rue Blaise Pascal, CS 90032, 67081 Strasbourg (France)

[b] Laboratoire des biomolécules, LBM, Département de chimie, École normale supérieure, PSL University,Sorbonne Université, CNRS, 75005 Paris, France

Supporting Information Placeholder

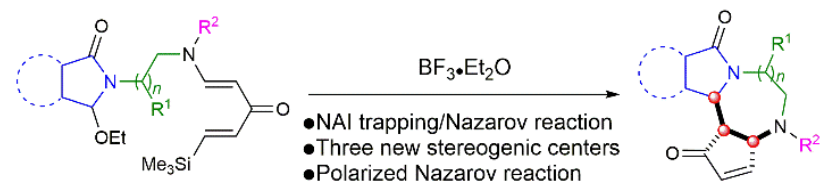

ABSTRACT: $N$-Acyliminium ions generated from enamidyl vinyl ketones provided cyclopentenoid-fused diazepines diastereoselectively using $\mathrm{BF}_{3} \cdot \mathrm{Et}_{2} \mathrm{O}$ in one pot through a domino $N$-acyliminium ion trapping/Nazarov reaction, simultaneously generating three new stereogenic centers. The particular structural design of the cross-conjugated dienone dictates the torquoselectivity observed in this polarized Nazarov reaction. Various $N$-bridgehead polycyclic scaffolds of putative pharmacological interest were obtained. Cyclic voltammetry was used to support the preferred reaction sequence within this domino reaction.

The $N$-bridgehead unit is a privileged structural motif in numerous biologically active molecules. $N$-Bridgehead diazepines are particularly relevant, displaying interesting pharmacological profiles such as those in (-)-DC-81, a psychoactive drug, ${ }^{[1]}$ Erchinine A and B antimicrobial agents, ${ }^{[2]}$ and the antitumor antibiotic Anthramycin ${ }^{[3]}$ (Figure 1). Construction of the $\mathrm{N}$ bridgehead diazepine unit in polyheterocyclic frameworks usually requires multistep approaches. Tertiary enamides are established as shelf-stable enamine variants ${ }^{[4]}$ and have been revealed to be good nucleophiles toward epoxides, ${ }^{[5]}$ carbonyls, ${ }^{[6]}$ imines ${ }^{[7]}$ nitrilium ions, ${ }^{[8]}$ activated alkynes ${ }^{[9]} \mathrm{N}$-acyliminium ions (NAI), ${ }^{[10]}$ and preformed carbocations ${ }^{[11]}$ to construct various nitrogen-containing molecules. In this regard, well-designed tertiary enamides may provide an efficient starting point for the synthesis of polyheterocyclic scaffolds involving a $\mathrm{N}$ bridgehead backbone. Our aim was to synthesize $N$-bridgehead diazepines fused with cyclopentenones of putative pharmacological interest using enamidyl vinyl ketones.

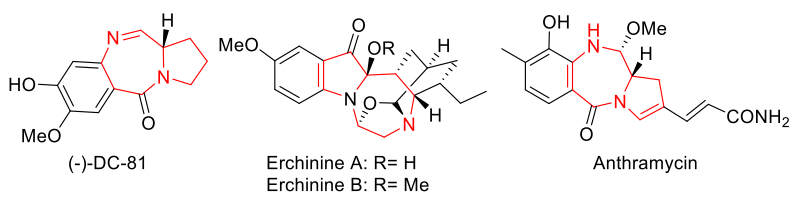

Figure 1. Biologically active $N$-bridgehead diazepines.

The Nazarov cyclization, known as a $4 \pi$ electrocyclization of cross-conjugated dienones, can be considered as one of the most powerful tools to produce cyclopentenones. ${ }^{[12]}$ In particular, to overcome the relatively low reactivity of divinyl ketones and to tune the torquoselectivity of the Nazarov cyclization, these substrates have been activated by adjacent heteroatoms to stabilize the oxyallyl cation. ${ }^{[12 c],[13]}$ Among those polarized Nazarov cyclizations, nitrogen-substituted cross-conjugated divinyl ketones at the $\alpha$-position have been frequently investigated.[14] In contrast, Nazarov cyclization involving dienones substituted with a nitrogen at the $\beta$-position are scarce. Cha and Kim reported a Nazarov cyclization of a $\beta$-aza-substituted divinyl ketone to achieve the synthesis of the tricyclic core present in cephalotaxine (Scheme 1, a). ${ }^{[15]}$ The endocyclic enamine cyclopentenone annulation for the synthesis of cephalotaxine reported by $\mathrm{Li}$ and Wang was also rationalized as an unusual Nazarov-type cyclization. (Scheme 1, b). ${ }^{[16]}$ Recently, we

Scheme 1. Nazarov Cyclizations involving $\beta$-Aza-Substituted Cross-Conjugated Divinyl Ketones.

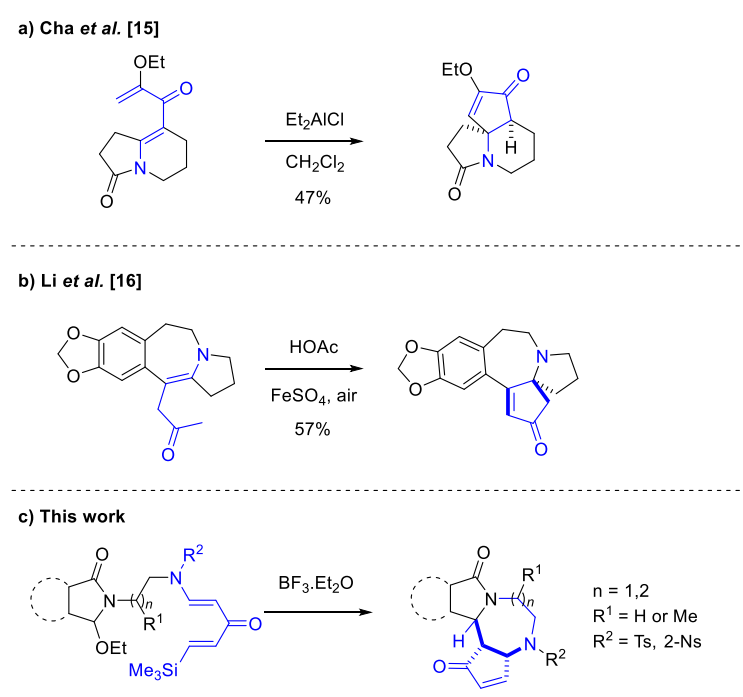


showed that $N$-acyliminium ions (NAI) derived from enamides undergo intramolecular TMSOTf-mediated trapping of the NAI to produce a variety of polyfunctionalized, medium-sized diazaheterocycles. ${ }^{[10]}$ We then anticipated that in acidic media, NAI precursors tethered with tertiary enamidyl vinyl ketones would offer the possibility of promoting two reactions simultaneously: nucleophilic addition of the enamide to the NAI and subsequent Nazarov reaction (Scheme 1, c).

To assess our domino reaction, we synthesized the requisite cross-conjugated dienones $\mathbf{1}$ by addition of sulfonamides on terminal alkynes by using Triton $\mathrm{B}^{[17]}$ or $\mathrm{DABCO}^{[18]}$ (see Suporting Information). Having the NAI precursor equipped with the cross-conjugated enamidyl vinyl ketone $\mathbf{1}$, we attempted to initiate the domino reaction by using $\mathrm{BF}_{3} \cdot \mathrm{Et}_{2} \mathrm{O}$ to generate the NAI. ${ }^{[20]}$ With the phenyl substituent, although the trapping of the $N$-acyliminium ion was efficient, the Nazarov reaction did not take place (Scheme 2).

Scheme 2. Nazarov Cyclizations involving $\beta$-Aza-Substituted Cross-Conjugated Divinyl Ketones.

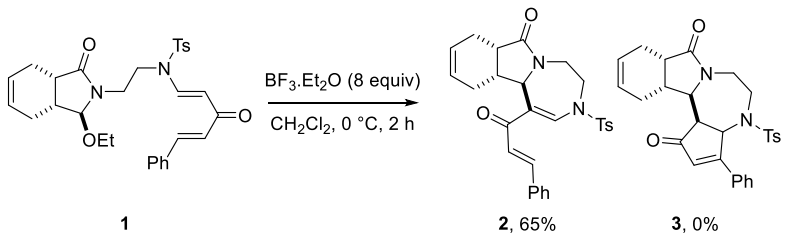

We rationalized that a divinyl ketone substituted with a silicon atom would provide an efficient solution to this issue by taking advantage of the $\beta$-silicon effect to facilitate the Nazarov reaction. ${ }^{[21]}(E)$-Configured ene-ynone $\mathbf{1 2 b}$ was obtained from prop2-yn-1-ol in a six-step reaction sequence with $37 \%$ overall yield (see Supporting Information). The desired $(E, E)$ cross-conjugated enamidyl vinyl ketone substrate 5a was obtained by reacting the corresponding tosylsulfonamide $4 \mathbf{a}$ with $E$ configured ene-ynone 12b in the presence of DABCO (Scheme 3). Gratifyingly, using $\mathrm{BF}_{3} \cdot \mathrm{Et}_{2} \mathrm{O}$, we obtained the desired tetracycle $\mathbf{6 a}$ as a single diastereomer in one pot from $N$-functionalized alkoxyamide 5a. The trapping of the $N$-acyliminium ion and the subsequent Nazarov reaction was achieved in 50\% yield, and the torquoselectivity was controlled via factors that are challenging to pinpoint owing to the peculiar structure of the crossconjugated dienone, thus leading stereoselectively to a single aza-polycyclic framework bearing three more stereogenic centers.

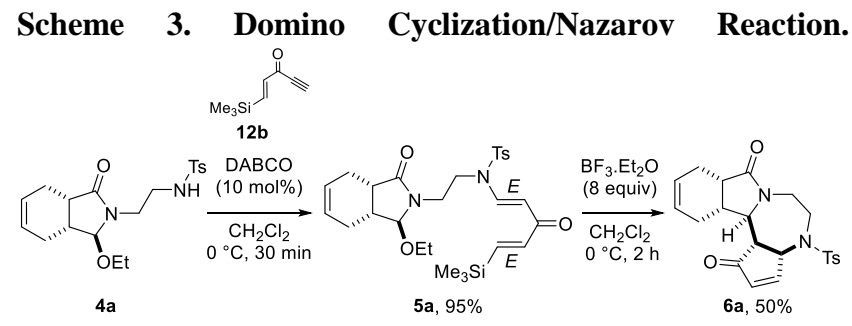

Screening of Lewis and Brønsted acids revealed that only a few Lewis acids were able to promote this domino reaction (Table 1 , entries 6 to 9). Brønsted acids such as $p$-TsOH, TfOH, $\mathrm{MeSO}_{3} \mathrm{H}$ (Table 1, entries 1-2, 3 and 4, respectively) led either to the starting material or degradation. We had more success with $\mathrm{BF}_{3} \cdot \mathrm{Et}_{2} \mathrm{O}$, although a minimum temperature of $0{ }^{\circ} \mathrm{C}$ is required (Table 1, entry 6 ), and a greater amount of the Lewis acid as well as a longer reaction time has a positive influence on the yield of the reaction (Table 1, entries 7 and 8, respectively). TMSOTf was as effective as $\mathrm{BF}_{3} \cdot \mathrm{Et}_{2} \mathrm{O}$ and provided the azafused polycyclic derivative in similar yields (Table 1, entry 9). Using Lewis acids such as $\mathrm{AlCl}_{3}, \mathrm{FeCl}_{3}$ and $\mathrm{Y}(\mathrm{OTf})_{3}$, the outcome for the domino reaction remained the same - degradation or no transformation (Table 1, entries 10, 11 and 12, respectively).

Table 1. Screening of Lewis and Brønsted Acids

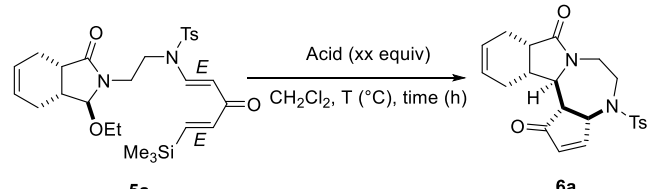

$\begin{array}{ccccc}\text { entry } & \text { acid (equiv) } & \begin{array}{c}\text { temp } \\ \left({ }^{\circ} \mathrm{C}\right)\end{array} & \text { time (h) } & \text { yield }(\%)^{a} \\ 1 & p \text {-TsOH (8) } & 0 \text { to rt } & 3 & -^{b} \\ 2 & p \text {-TsOH (8) } & 0 \text { to rt } & 6 & \text { traces } \\ 3 & \mathrm{TfOH}(8) & 0 & 4 & -^{c} \\ 4 & \mathrm{MeSO}_{3} \mathrm{H}(8) & 0 & 1 & -^{c} \\ 5 & \mathrm{BF}_{3} \bullet \mathrm{Et}_{2} \mathrm{O}(8) & -30 & 2 & -^{b} \\ 6 & \mathrm{BF}_{3} \bullet \mathrm{Et}_{2} \mathrm{O}(8) & 0 & 2 & 50 \\ 7 & \mathrm{BF}_{3} \bullet \mathrm{Et}_{2} \mathrm{O}(8) & 0 & 6 & 77 \\ 8 & \mathrm{BF}_{3} \cdot \mathrm{Et}_{2} \mathrm{O}(10) & 0 & 6 & 85 \\ 9 & \mathrm{TMSOTf} \mathrm{(8)}_{10} & 0 & 4 & 85 \\ 10 & \mathrm{AlCl}_{3}(8) & 0 & 6 & -^{c} \\ 11 & \mathrm{FeCl}_{3}(8) & 0 & 2 & -^{c} \\ 12 & {\mathrm{Y}(\mathrm{OTf})_{3}(8)}^{c} & 0 & 6 & -^{b}\end{array}$

${ }^{a}$ Isolated yields. ${ }^{b}$ Starting material $\mathbf{5 a}$ was fully recovered. ${ }^{c}$ Degradation observed.

The $N$-bridged diazepines bearing a cyclopentenone ring 6a-n were obtained with yields from 41 to $89 \%$ through this domino cyclization/Nazarov reaction (Scheme 4). We noticed that this domino reaction was completely diastereoselective, as only one polycyclic diazepine was obtained in each case. The methylated compound $\mathbf{5 m}$ led to a unique aza-fused polycyclic system $\mathbf{6 m}$ bearing four stereogenic centers. The protecting group on the nitrogen moiety of the tertiary enamide was also investigated to facilitate post-annulation deprotection - modification of the protecting group showed no influence on the outcome of the reaction. Diazepine $\mathbf{6 l}$ was obtained with a poorer yield than for compound 6a. Three methylene units for the spacer length were also allowed, providing an eight-membered fused polycyclic system 6n. The homolog 30 with four methylene units did not undergo this domino reaction. In this case, elimination of EtOH took place leading to the more stable conjugated alkene $7 .^{[22]}$ The X-ray structures of compounds $\mathbf{6 b}, \mathbf{6 h}$ and $\mathbf{6 n}$ corroborated the assigned structures. ${ }^{[23]}$

Regarding the mechanism involved, the sequence of the reactions was uncertain: Nazarov reaction and subsequent addition on the NAI (Scheme 5, A) or trapping of NAI with enamide and consecutive Nazarov reaction (Scheme 5, B). Both sequences would lead to the same compound 6. 

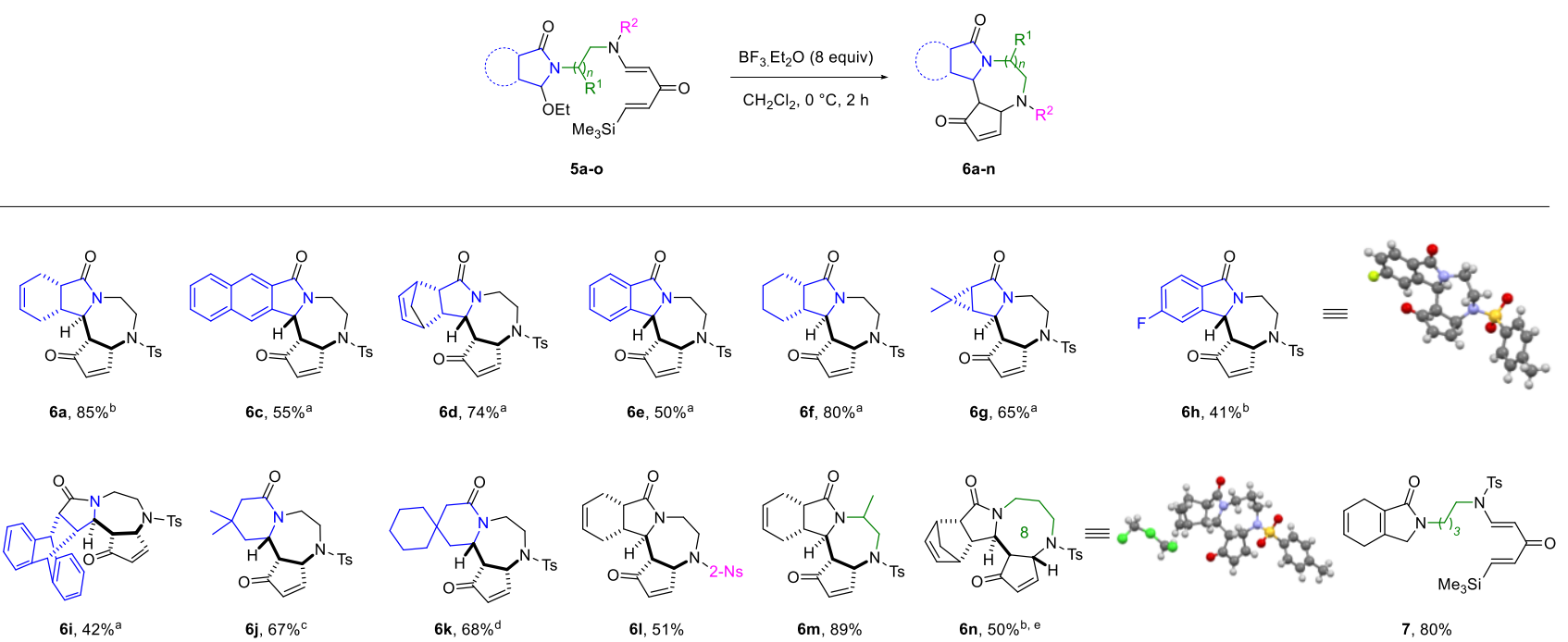

${ }^{\text {a }}$ Isolated yields; ${ }^{\mathrm{b}}$ See [23] for CCDC deposition numbers; ${ }^{\mathrm{c}} 2 \mathrm{~d}$ at rt; ${ }^{\mathrm{d}} 3 \mathrm{~d}$ at rt; ${ }^{\mathrm{e}} \mathbf{6 n}$ co-crystallized with one molecule of $\mathrm{CH}_{2} \mathrm{Cl}_{2}$.

To gain more insight into the preferred reaction sequence, cyclic voltammetry (CV) was employed to assess the affinity of the Lewis acid for the $N$-acyliminium precursor and for the enamidyl vinyl ketone. For this purpose, two mimics of these moieties were prepared (Scheme 5): 8 for the aminal precursor of the acyliminium and $\mathbf{9}$ for the enamidyl vinyl ketone.

Scheme 5. Two plausible Pathways for the Domino Reaction.

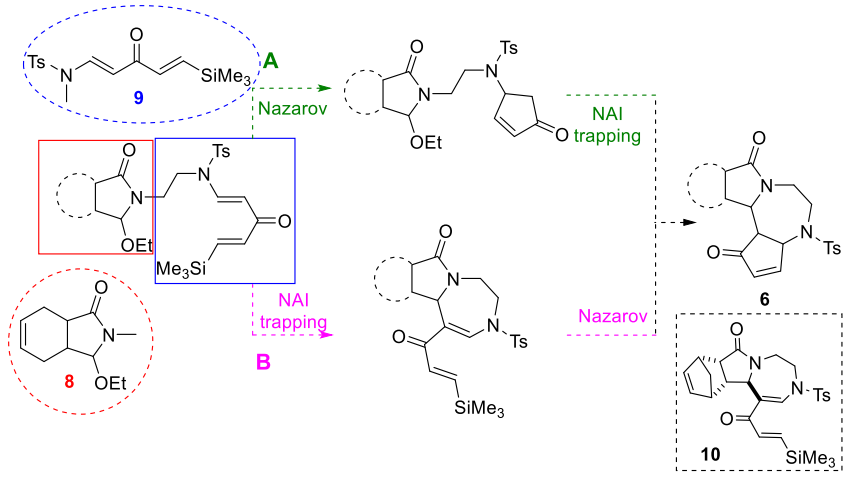

The latter could be characterized by its reduction peak potential at $-1.6 \mathrm{~V}$ vs SCE (saturated calomel electrode) in $\mathrm{CH}_{2} \mathrm{Cl}_{2}$. The $\mathrm{CV}$ pattern instantaneously evolved after addition of 1 equivalent of $\mathrm{BF}_{3} \cdot \mathrm{OEt}_{2}$ with a less cathodic reduction peak at $-1.3 \mathrm{~V}$ vs SCE (Figure 2 left). However, when adding the Lewis acid in the presence of $\mathbf{8}$, no modification of the $\mathrm{CV}$ was observed just after addition of $\mathrm{BF}_{3} \bullet \mathrm{OEt}_{2}$ (Figure 2 right). This implies that in the presence of $\mathbf{8 , 9}$ does not interact with the Lewis acid, consistent with an enhanced affinity of $\mathbf{8}$ compared to $\mathbf{9}$. These results and production of a limited amount of non-cyclized dienone $\mathbf{1 0}$ by shortening the reaction time, provide evidence that route $\mathrm{B}$ is the more likely mechanistic pathway.

To explain the one-pot formation of fused polycyclic ring system $\mathbf{6 a}$, the mechanism outlined in Scheme 6 is thus proposed. Regarding the relative stereochemistry and according to the NMR studies and the X-ray structures, two trends were observed. With lactam rings fused to conformationally more flexible rings (compounds $\mathbf{6 a}, \mathbf{6 f}, \mathbf{6 i}, \mathbf{6 l}$, and $\mathbf{6 m}$ ), a trans relationship between lactam proton $\left(\mathrm{H}_{1}\right)$ and the two ring junction
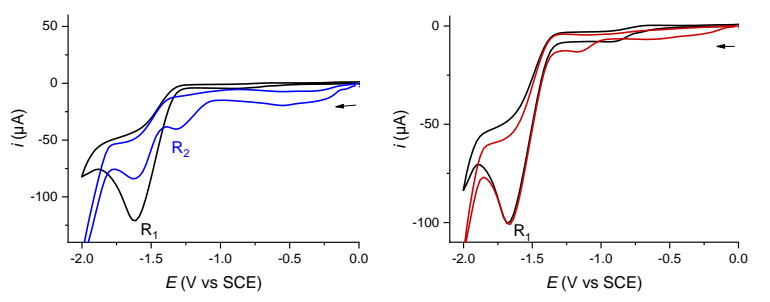

Figure 2. Cyclic voltammetry $(\mathrm{CV})$ performed toward reduction potential of a $4 \mathrm{mM}$ solution in $\mathrm{CH}_{2} \mathrm{Cl}_{2}$ containing $0.1 \mathrm{M}$ of $n$ $\mathrm{Bu}_{4} \mathrm{NBF}_{4}$ using a glassy carbon working electrode $(\mathrm{d}=3 \mathrm{~mm})$ with a $\mathrm{Pt}$ wire as counter-electrode and saturated calomel electrode (SCE) as reference electrode, at a scan rate of $0.1 \mathrm{~V} \mathrm{~s}^{-1}$ at $20{ }^{\circ} \mathrm{C}$. Left: Black curve: 9 alone, Blue curve: 9 with 1 equivalent of $\mathrm{BF}_{3} \cdot \mathrm{OEt}_{2}$ at rt. Right: Black curve: $\mathbf{9}$ with 1 equivalent of $\mathbf{8}, \mathrm{Red}$ curve: 9 with 1 equivalent of 8 and 1 equivalent of $\mathrm{BF}_{3} \cdot \mathrm{OEt}_{2}$ at rt.

protons $\left(\mathrm{H}_{2}\right.$ and $\left.\mathrm{H}_{3}\right)$ was observed. Whereas with lactam rings fused to conformationally more rigid cycles, i.e., more conformationally constrained environment (compounds $\mathbf{6 c}, \mathbf{6 d}, \mathbf{6 e}, \mathbf{6 h}$, $\mathbf{6 j}$, and $\mathbf{6 k}$ ), a cis relationship between the lactam proton $\left(\mathrm{H}_{1}\right)$ and the two ring junction protons $\left(\mathrm{H}_{2}\right.$ and $\left.\mathrm{H}_{3}\right)$ was observed. Treatment of dienone 5a with the Lewis acid provides the $N$ acyliminium ion $\mathbf{A}$. In this case, the prochiral iminium ion $\mathbf{A}$ will be attacked from the less hindered side by the tertiary enamide (convex face) leading to iminium ion $\mathbf{B}$. After deprotonation, the cross-conjugated dienone $\mathbf{C}$ undergoes tertiary enamide-assisted Nazarov cyclization.

Indeed, the presence of the nitrogen moiety at the divinyl ketone lowers the energy barrier for the formation of the oxyallyl cation, allowing the Nazarov reaction to take place at $0{ }^{\circ} \mathrm{C}$ or $\mathrm{rt} .{ }^{14 \mathrm{~b}, \mathrm{f}}$ Once the stereochemistry of the aminal proton $\left(\mathrm{H}_{1}\right)$ is set, clockwise, conrotatory ring closure of $\mathbf{D}$ pushes down the newly formed five-membered boron enolate $\mathbf{E}$. The latter evolves upon $\beta$-silyl-elimination, and protonation will occur from the less hindered convex face, thus generating the thermodynamically more stable cis fused 5-7 membered polycyclic system $\mathbf{6 a}$. 


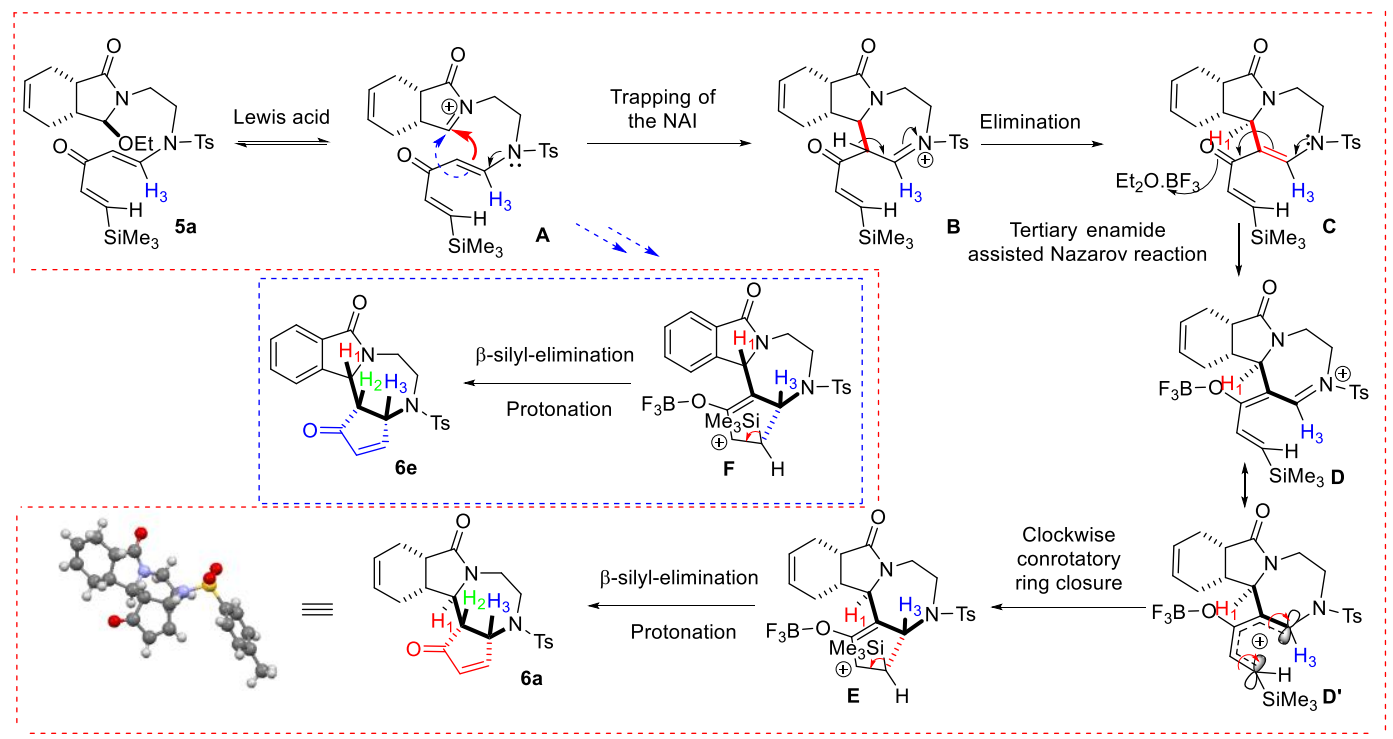

In the case of divinyl ketone $\mathbf{5 e}$, the conformationally constrained environment of the lactam will induce an attack from the enamide under the plane of the lactam as drawn, thus pushing the lactam proton $\mathrm{H}_{1}$ above the plane of the lactam moiety, also pushing down the newly formed five-membered boron enolate $\mathbf{F}$, through a clockwise conrotatory ring closure. Protonation of $\mathbf{F}$ will occur to generate the thermodynamically more stable cis fused 5-7 membered polycyclic system 6e. Compound 6n involving an 8-membered ring shows an unusual cistrans behavior and would be structurally related to the lactams fused to a flexible ring, but protonation of the enol-boronate occurs from the less hindered side and thus provides a trans ring junction because of the presence of the diazocane.

In conclusion, we have shown that NAI generated from tertiary enamidyl vinyl ketones undergo cyclization followed by tertiary enamide-assisted Nazarov cyclization to afford in each case a single diastereomeric polycyclic diazepine bearing a cyclopentenone ring. Torquoselectivity of the domino reaction can be attributed to the particular design of the divinyl ketones involved. Various NAI precursors as well as different chain lengths were accommodated. Electrochemical experiments revealed a higher affinity of the Lewis acid for the aminal part of the substrate than for the divinyl part, thus corroborating the order of the reaction sequence within the domino reaction.

\section{ASSOCIATED CONTENT}

\section{Supporting Information}

The Supporting Information is available free of charge on the ACS Publications website.

Supporting information (PDF)

CCDC 1831780, 2001081 and 2001082 contain the supplementary crystallographic data for this paper. These data can be obtained free of charge via www.ccdc.cam.ac.uk/data_request/cif, or by emailing data_request@ccdc.cam.ac.uk, or by contacting The Cambridge Crystallographic Data Centre, 12 Union Road, Cambridge CB2 1EZ, UK; fax: +44 1223336033.

\section{AUTHOR INFORMATION}

\section{Corresponding Author}

*1miesch@unistra.fr

\section{Present Addresses}

†Organic Synthesis, Department of Organic and Macromolecular Chemistry, Ghent University, Krijgslaan 281, S4, 9000 Gent, Belgium.

\section{Author Contributions}

$\$$ These authors contributed equally.

\section{ACKNOWLEDGMENT}

Support for this work was provided by CNRS and Université de Strasbourg. Y.Z thanks CSC for a research fellowship. L. A thanks M.R.T. for a research fellowship. The authors thank Dr. Xavier Salom Roig from the Institut des Biomolécules Max Mousseron -University of Montpellier for fruitful discussions.

\section{REFERENCES}

[1] M. Pardo, I. Tellitu, E. Domínguez, Tetrahedron 2010, 66, 5811-5818.

[2] H.-F. Yu, X.-J. Qin, C.-F. Ding, X. Wei, J. Yang, J.-R. Luo, L. Liu, A. Khan, L.-C. Zhang, C.-F. Xia, X.-D. Luo, Org. Lett. 2018, 20, 4116-4120.

[3] T. Kaneko, H. Wong, T. W. Doyle, W. C. Rose, W. T. Bradner, J. Med. Chem. 1985, 28, 388-392.

[4] a) M.-X. Wang, Chem. Commun. 2015, 51, 6039-6049 and references therein; b) X. Cai, M. Yang, H. Guo, Curr. Org. Synth. 2019 , $16,70-97$.

[5] a) K. N. Cossey, R. L. Funk, J. Am. Chem. Soc. 2004, 126, 12216-12217; b) L. Yang, Q.-Y. Zheng, D.-X. Wang, Z.-T. Huang, M.X. Wang, Org. Lett. 2008, 10, 2461-2464; c) L. Yang, D.-X. Wang, Q.Y. Zheng, J. Pan, Z.-T. Huang, M.-X. Wang, Org. Biomol. Chem. 2009, 7, 2628-2634.

[6] a) L. Yang, D.-X. Wang, Z.-T. Huang, M.-X. Wang, J. Am. Chem. Soc. 2009, 131, 10390-10391; b) L. Yang, C.-H. Lei, D.-X. Wang, Z.-T. Huang, J. Zhu, M.-X. Wang, Org. Lett. 2010, 12, 39183921; c) S. Tong, D.-X. Wang, L. Zhao, J. Zhu, M.-X. Wang, Angew. Chem. Int. Ed. 2012, 51, 4417-4420.

[7] a) S. Suga, T. Nishida, D. Yamada, A. Nagaki, J.-I. Yoshida, J. Am. Chem. Soc. 2004, 126, 14338-14339; b) S. Tong, X. Yang, D.- 
X. Wang, L. Zhao, J. Zhu, M.-X. Wang, Tetrahedron 2012, 68, 64926497.

[8] a) C.-H. Lei, D.-X. Wang, L. Zhao, J. Zhu, M.-X. Wang, J. Am. Chem. Soc. 2013, 135, 4708-4711; b) C.-H. Lei, D.-X. Wang, L. Zhao, J. Zhu,

M.-X. Wang, Chem. - Eur. J. 2013, 19, 16981-16987; c) C.-H. Lei, L. Zhao, D. X. Wang, J. Zhu, M.-X. Wang, Org. Chem. Front. 2014, 1 , 909-913.

[9] a) T. J. Harrison, B. O. Patrick, G. R. Dake, Org. Lett. 2007, 9, 367-370; b) S. Nayak, B. Prabagar, N. Ghosh, R. K. Mallick, A. K. Sahoo, Synthesis 2017, 49, 4261-4271.

[10] L. Andna, L. Miesch, Org. Lett. 2018, 20, 3430-3433.

[11] F. Beltran, L. Miesch, Org. Lett. 2019, 21, 1569-1573.

[12] a) K. L. Habermas, S. E. Denmark, T. K. Jones in Organic Reactions, Vol 45 (Ed: L. A. Paquette), J. Wiley \& Sons, 1994, pp. 2158; b) H. Pellissier, Tetrahedron 2005, 61, 6479-6517; c) A. J. Frontier, C. Collison, Tetrahedron 2005, 61, 7577-7606; d) T. N. Grant, C. J. Rieder, F. G. West, Chem. Commun. 2009, 5676-5688; e) T. Vaidya, R. Eisenberg, A. J. Frontier, ChemCatChem 2011, 3, 1531-1548; f) W. T. Spencer III, T. Vaidya, A. J. Frontier Eur. J. Org. Chem. 2013, 36213633; g) D. R. Wenz, J. R. de Alaniz, Eur. J. Org. Chem. 2015, 23-37; h) M. C. Martin, R. Shenje, S. France, Isr. J. Chem. 2016, 56, 499-511; i) M. G. Vinogradov, O. V. Turova, S. G. Zlotin, Org. Biomol. Chem. 2017, 15, 8245-8269.

[13] a) W. He, X. Sun, A. J. Frontier, J. Am. Chem. Soc. 2003 125, 14278-14279; b) G. Liang, S. N. Gradl, D. Trauner, Org. Lett. 2003, 5, 4931-4934; c) C. Bee, E. Leclerc, M. A. Tius, Org. Lett. 2003, 5, 4927-4930; d) S. Raja, W. Ieawsuwan, V. Korotkov, M. Rueping, Chem. - Asian J. 2012, 7, 2361-2366; e) G. E. Hutson, Y. E. Türkmen, V. H. Rawal, J. Am. Chem. Soc. 2013, 135, 4988-4991; f) J. J. Koenig, T. Arndt, N. Gildemeister, J.-M. Neudörfl, M. Breugst, J. Org. Chem. 2019, 84, 7587-7605.

[14] a) E. G. Occhiato, C. Prandi, A. Ferrali, A. Guarna, J. Org. Chem. 2005, 70, 4542-4545; b) D. J. Kerr, M. Miletic, J. H. Chaplin, J. M. White, B. L. Flynn, Org. Lett. 2012, 14, 1732-1735; c) Y.-K. Wu,
T. Niuz, F. G. West, Chem. Commun. 2012, 48, 9186-9188; d) B. L. Flynn, N. Manchala, E. H. Krenske, J. Am. Chem. Soc. 2013, 135, 9156-9163; e) D. Scarpi, M. Petrović, B. Fiser, E. Gómez-Bengoa, E. G. Occhiato, Org. Lett. 2016, 18, 3922-3925; f) N. Manchala, H. Y. L. Law, D. J. Kerr, R. Volpe, R. J. Lepage, J. M. White, E. H. Krenske, B. L. Flynn, J. Org. Chem. 2017, 82, 6511-6527; g) G.-P. Wang, M.Q. Chen, S.-F. Zhu, Q.-L. Zhou, Chem. Sci. 2017, 8, 7197-7202; h) P. N. Carlsen, E. G. Stoutenburg, A. J. Frontier, Synthesis 2018, 50, 12381245 .

[15] S.-H. Kim, J. K. Cha, Synthesis 2000, 14, 2113-2116.

[16] W.-D. Z. Li, Y.-Q. Wang, Org. Lett. 2003, 5, 2931-2934.

[17] L. Andna, L. Miesch, Org. Biomol. Chem. 2019, 17, 56885692.

[18] S. J. Gharpure, V. Prasath, V. Kumar, Chem. Commun. 2015, 51, 13623-13626.

[19] Y. Koseki, K. Fujino, A. Takeshita, H. Sato, T. Nagasaka, Tetrahedron: Asymmetry 2007, 18, 1533-1536.

[20] a) W. N. Speckamp, M. J. Moolenaar, Tetrahedron 2000, 56, 3817-3856; b) S. G. Pyne, C. W. G. Au, A. S. Davis, I. R. Morgan, T. Ritthiwigrom, A. Yazici, Pure Appl. Chem. 2008, 80, 751-762; c) I. R. Morgan, A. Yazici, S. G. Pyne, B. W. Skelton, J. Org. Chem. 2008, 73, 2943-2946; d) I. R. Morgan, A. Yazici, S. G. Pyne, Tetrahedron 2008, 64, 1409-1419; e) P. Wu, T. E. Nielsen, Chem. Rev. 2017, 117, 78117856.

[21] a) S. E. Denmark, T. K. Jones, J. Am. Chem. Soc. 1982, 104, 2642-2645; b) M. Miesch, L. Miesch-Gross, M. Franck-Neumann, Tetrahedron 1997, 53, 2103-2110; c) M. Miesch, L. Miesch-Gross, M. Franck-Neumann, Tetrahedron 1997, 53, 2111-2118.

[22] J. B. P. A. Wunberg, H. E. Schoemaker, W. N. Speckamp, Tetrahedron 1978, 34, 179-187.

[23] CCDC 1831780 (6a), CCDC $2001081(\mathbf{6 h})$ and CCDC $2001082(\mathbf{6 n})$ contain the supplementary crystallographic data for this paper. These data can be obtained free of charge from The Cambridge Crystallographic Data Centre. 